\title{
Microbial landscapes on the outer tissue surfaces of the reef-building coral Porites compressa
}

\author{
I. S. Johnston · F. Rohwer
}

Received: 10 August 2006 / Accepted: 9 February 2007 / Published online: 13 March 2007

(C) Springer-Verlag 2007

\begin{abstract}
Microbial-coral interactions are increasingly recognized as important for coral health and disease. Visualizing these interactions is important for understanding where, when, and how the coral animal and microbes interact. Porites compressa, preserved using Parducz fixative and examined by scanning electron microscopy, revealed a changing microbial landscape. The external cell layers of this coral were invariably clean of directly adhering microbes, unlike coral-associated mucus. In colonies with expanded polyps, secreted mucus rapidly dissipated, although blobs of new mucus were common; the coral epidermal cells expressed cilia, which are presumably used to clean the surface, and coral-associated microbes were present as flocs, possibly enmeshed in mucus. In colonies with permanently contracted polyps, the coral epidermis had lost cilia and a stable, multi-lamellar mucous sheet covered the surface of the animal. This sheet became heavily colonized by both prokaryotic and eukaryotic microbes, however these microbes did not penetrate the mucous sheet and the animal's epidermal cell surfaces remained sterile. These observations show that relationships between this coral animal and associated microbes are highly dynamic.
\end{abstract}

Keywords Porites $\cdot$ Reef-coral $\cdot$ Mucus $\cdot$ Microbes $\cdot$ SEM

Communicated by Biology Editor H.R. Lasker.

I. S. Johnston ( $\square)$

Department of Biological Sciences,

Bethel University, 3900 Bethel Dr.,

St Paul, MN 55112, USA

e-mail: i-johnston@bethel.edu

F. Rohwer

Biology Department, LS301, San Diego State University,

5500 Campanile Dr., San Diego, CA 92182, USA

\section{Introduction}

There is growing appreciation for the fundamental dependence that all biomes have upon their microbial constituents, and this is especially true for marine ecosystems in general and coral reef ecosystems in particular (Azam and Worden 2004). A major contribution to this growing appreciation is the rapid development of molecular genetic tools to assess the sheer diversity, population numbers and metabolic interactions of marine microbes. Bacteria are the most diverse and numerous organisms associated with reef-building corals; sequencing of $16 \mathrm{~S}$ rDNA from just 14 coral specimens from three species of reef-building corals yielded 430 distinct bacterial ribotypes (Rohwer et al. 2002). Coralassociated Archaea are also numerous and diverse (Kellogg 2004; Wegley et al. 2004). These microbes (presumably together with viruses and protists) are not just contaminants from the overlying reef waters (Rohwer et al. 2001), but rather consist of commensal and endosymbiotic forms comprising an integrated holobiont together with the scleractinian host (Rohwer and Kelly 2004).

Two major types of sampling protocol have been used to investigate coral-associated microbes: whole-animal (holobiont) maceration, and either syringe-aspiration of coral surface material or washings of the coral surface. The maceration techniques range from water picking or airbrushing of soft tissues to whole specimen (including underlying skeletal material) pestle-grinding. These protocols are prone to microbial contamination from bathing seawater, but more importantly the physical organization of any epifaunal community would likely be disrupted by most of these sampling regimens.

Living corals are often described as being slick with mucous secretions. Mucus on the surface of coral colonies has been implicated in a variety of coral behaviors and 
physiological strategies, including desiccation resistance, sediment removal, and detrital/particulate feeding, etc., (see the recent comprehensive review by Brown and Bythell 2005). Mucus components identified as dissolvable organic material (DOM), and mucus-enriched flocs identified as particulate organic material (POM), released from corals, are both thoroughly implicated in overall energy budgets for reef ecosystems (Wild et al. 2004). Secreted mucus, whether still closely associated with the surface of a coral, or not, invariably becomes enriched with microbes in comparison with the overlying water column (Coffroth 1990). Species of the genus Porites are particularly prone to acquiring transient mucous sheets, over broad areas of colony surface. These sheets develop naturally on a reef (Coffroth 1991), under experimental conditions of sediment loading in running seawater systems (Coffroth 1985), and with unpredictable frequency in well-maintained reef aquaria (Delbeek and Sprung 1994). The end-stage of these sheets is their release from the coral surface as microbially fouled ragged remnants, which slough off into the water column as unstable threads (cf Coles and Strathmann 1973). Similar cycles of mucus sheath formation and bacterial colonization occur in the gorgonian Briarium asbestinum (Rublee et al. 1980).

Even as the biological complexity of reef ecosystems is only partially understood, and the microbial dimensions are even less appreciated, coral reefs worldwide are in a dramatic state of decline (Wilkinson 2004). Anthropogenic influences are strongly implicated on both local and global scales, from local nutrient and/or organic enrichment of the water bathing reefs (Richmond 1993) to global warming leading to rising sea-surface temperatures (see review by Jokiel 2004). Some expressions of the decline of reef communities are increased coral disease incidence and emerging diseases of corals, some of which correlate with expanded populations of specific bacterial pathogens in disease lesions (e.g., Patterson et al. 2002). Study of the histopathology of coral diseases, and conversations about potential interventions to alleviate coral diseases, are both proceeding in relative ignorance of a normal microbial flora associated with healthy corals. One feature of this normal flora might be its potential for structural association with the coral animal, e.g. do these microbes form a biofilm, or some kind of adherent community on the surface of the coral, or might they simply be present as a dynamic swarm in the boundary layers of water bathing the coral? This present study was designed to visualize any adherent microbial presence on the surface of normal, presumedhealthy, Porites compressa using scanning electron microscopy (SEM).

\section{Materials and methods}

Samples

Terminal branches from multiple colonies of $P$. compressa were harvested from the reef around Coconut Island (Moku O Lo'e), Kane'ohe Bay, Oahu, and held in running-seawater aquaria at the Hawaii Institute of Marine Biology (HIMB). Branch tips, 5-8 $\mathrm{mm}$ in diameter and less than $10 \mathrm{~mm}$ long, were sub-sampled with bone shearers, and mounted on plastic splints with a loop of $5 \mathrm{lb}$-strength monofilament nylon. To reduce the size of sub-sampled tips, only colonies with the thinnest terminal branches were used in this study. These tips were stored in racks in the same running-seawater aquaria, and were observed daily for polyp expansioncontraction cycles. Mounting on splints made it possible to manipulate these samples, subsequently, with minimal disturbance or mechanical abrasion of the soft-tissue surface.

On each of two collecting trips (June 2004 and July 2005) a limited number of splinted specimens (dictated by permits for field collection and hazardous waste generation) were fixed for electron microscopy. They were evenly distributed among three different observed living states at the time of fixation: corals with expanded polyps; those with permanently contracted polyps; and those with fouled microbial sheaths (cf Rublee et al. 1980 "states \#1, \#2 and \#3").

Fixation and electron microscopy

Coral tissues were fixed by rapid immersion in a modified Parducz solution (6 parts, $2 \%$ osmium tetroxide in $0.2 \mu \mathrm{m}$ filtered seawater: 1 part, saturated aqueous mercuric chloride) for $60 \mathrm{~min}$ (Johnston and Hildemann 1982). After fixation, the specimens were washed 3 times for $15 \mathrm{~min}$ in $0.2 \mu \mathrm{m}$-filtered seawater, dehydrated with $70 \%$ ethanol and stored for up to 4 days at $4^{\circ} \mathrm{C}$. The final dehydration was performed in graded ethanol solutions up to $100 \%$ ethanol, at which point some specimens were cryofractured in a frozen glass of liquid- $\mathrm{N}_{2}$-cooled ethanol (Humphreys et al. 1974). All coral fragments were then critical-point-dried with liquid $\mathrm{CO}_{2}$, mounted on aluminum stubs (while most were still attached to the original splints), and sputtercoated with gold and palladium. SEM examination was performed with either a Hitachi S-2700 scanning electron microscope (San Diego State University) or a Hitachi S-4700, field emission gun scanning electron microscope (Institute of Technology Characterization Facility, University of Minnesota). 


\section{Results}

\section{General features of $P$. compressa}

The scleractinian coral P. compressa is common in Hawaiian waters (Fenner 2005) and is the major frameworkbuilder on the shallow reefs surrounding Coconut Island, Kane'ohe Bay. Expanded polyps have a crown of 12 tentacles $(<3 \mathrm{~mm}$ diameter; Fig. 1a) protruding from skeletal calices $(<1.7 \mathrm{~mm}$ diameter). In some colonies the coenenchyme of the rims of the calices of terminal branches featured dense aggregations of white reflective granules. At first glance these might give the appearance of white skeletal elements showing through a transparent body wall, but this was not the case. Careful examination of living specimens with a dissecting microscope clearly distinguished underlying calcium carbonate skeleton from these white granules in the body wall of the coral. The same white reflective granules were present in the polyp tentacles too.
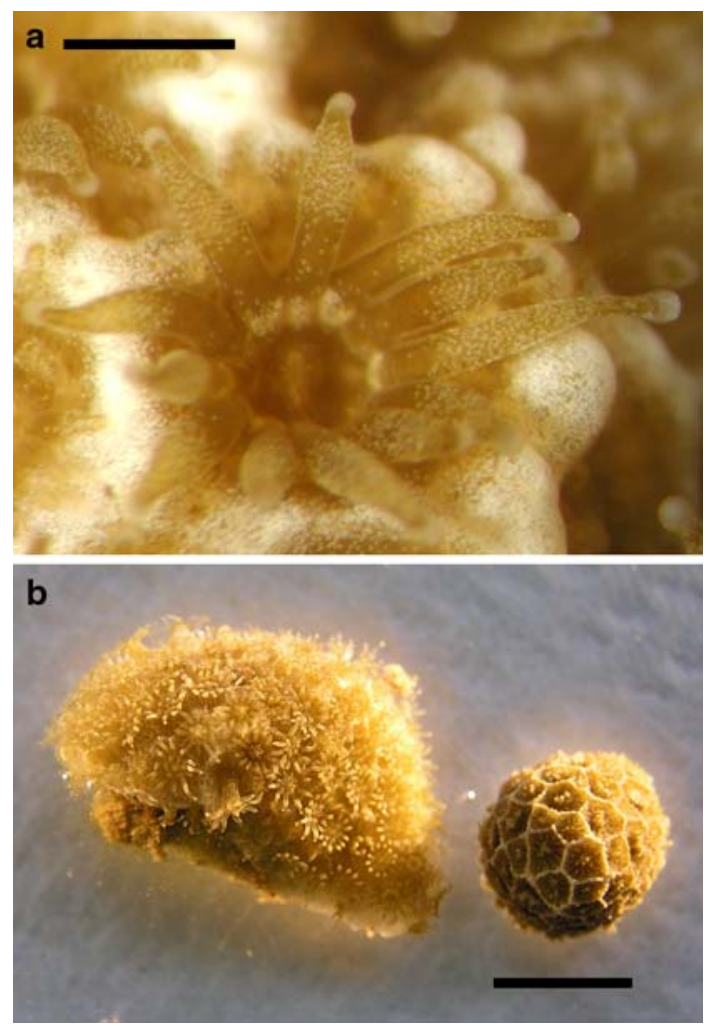

Fig. 1 a Macro-photograph of an expanded Porites compressa polyp. The expanded bulbs at the ends of each tentacle represent batteries of nematocysts. The brown coloration maps the visible distribution and density of zooxanthellae. The light patches on the tentacles and the denser white reflective areas around the rim of the skeleton calice represent accumulations of a granular white material within the tissue of the coral. Scale bar $=0.5 \mathrm{~mm}$. b Two colony-branch tips of $P$. compressa living under identical running-sea-water aquarium conditions, in one specimen all the polyps are expanded but in the other, the polyps have been permanently contracted for at least $8 \mathrm{~h}$ prior to the photograph. Scale bar $=5 \mathrm{~mm}$
Expanded polyps could be resolved by the unaided human eye, but the contracted polyps blended in with the coenenchyme and the contracted tentacles were merely tiny tufts marked by concentrated zooxanthellar pigment (Fig. 1b). In the early stages of mucous sheet formation it was difficult to discriminate visually between polyps that were permanently contracted beneath a sheet and polyps that had been transiently withdrawn. Therefore references to contracted coral specimens in this report are restricted to corals that had been in permanently contracted state for at least 8 hours at the time of fixation.

The noxious agents present in chemical fixatives (e.g., glutaraldehyde, commonly used in primary fixatives for conventional electron microscopy) usually cause living corals to contract into their skeleton before the coral's structural and metabolic components are inactivated and chemically preserved. However, the modified Parducz fixative used here was so fast-acting that it caught expanded polyps in a state of only partial shortening of the tentacles (Fig. 2a). Even so, some previously expanded polyps did contract in the process of handling their mounting splints prior to emersion in the fixative. Features on coenenchymal regions of a coral colony surface (i.e., tissue surfaces between individual polyps) were less sensitive to gross morphological changes triggered by polyp retraction, and were therefore exclusively considered in the following descriptions.

\section{Surfaces of expanded $P$. compressa}

The most prominent features of the tissue surfaces of expanded colonies were cilia protruding from the epidermal cells (Fig. 2b, c). The body wall of the coral consisted of a one-cell-thick layer of epidermal cells (comprising a mixed population of mucocytes and epidermal supporting cells) and a single layer of gastrodermal cells separated by mesogloea (Fig. 2b). Figure 2c shows that when the lateral boundaries of individual epidermal cells were resolved it was clear that each cell had a single cilium. Multiple microvilli (ranging from $0.2-0.7 \mu \mathrm{m}$ in length) were found along the lateral intercellular boundaries of these cells and around the bases of the cilia.

Evidence of any adherent material on the surface of expanded corals was limited to occasional sample areas with flocs of detritus (Fig. 2d). These flocs were sometimes seen as elongate ropes made up of multiple flocs (Fig. 2e). Resolving the individual particles in these flocs was technically difficult since they had only tenuous contact with the underlying material and therefore they were prone to charging in the electron beam of the microscope. The best resolution images indicated densely packed particles in the size-range of $0.1-0.2 \mu \mathrm{m}$-diameter, organized into irregular clusters (Fig. 2f). 


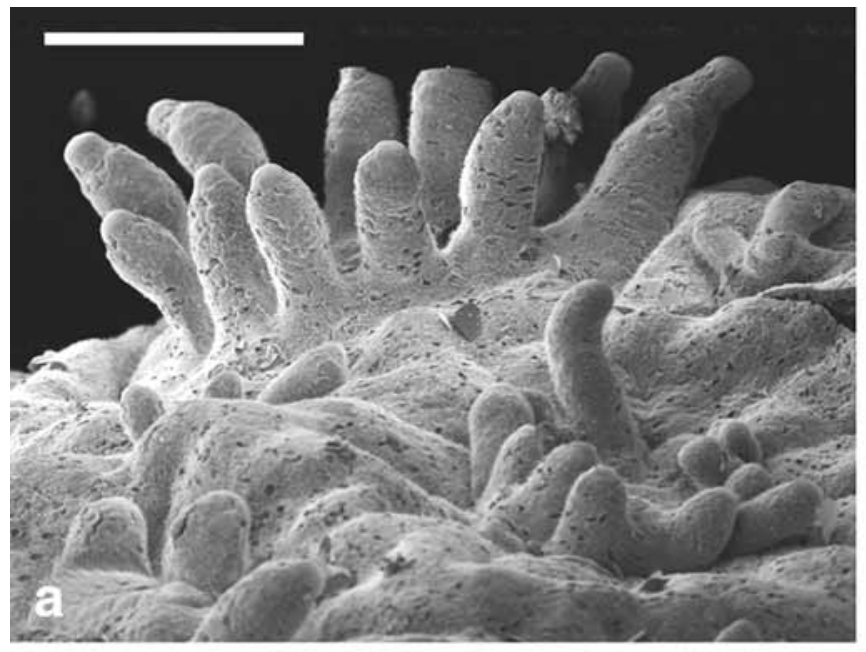

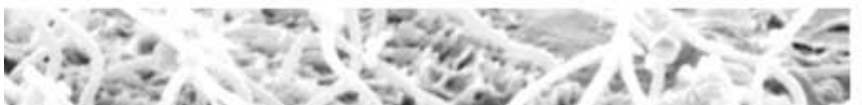
cisez a

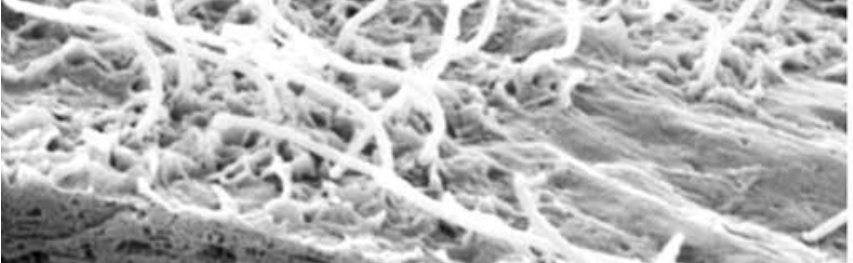

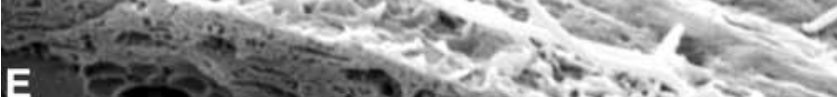

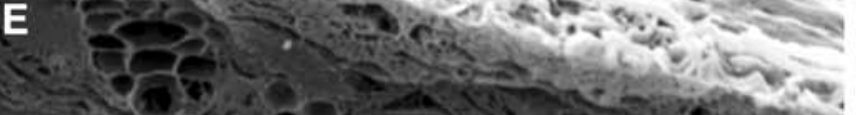

G

b

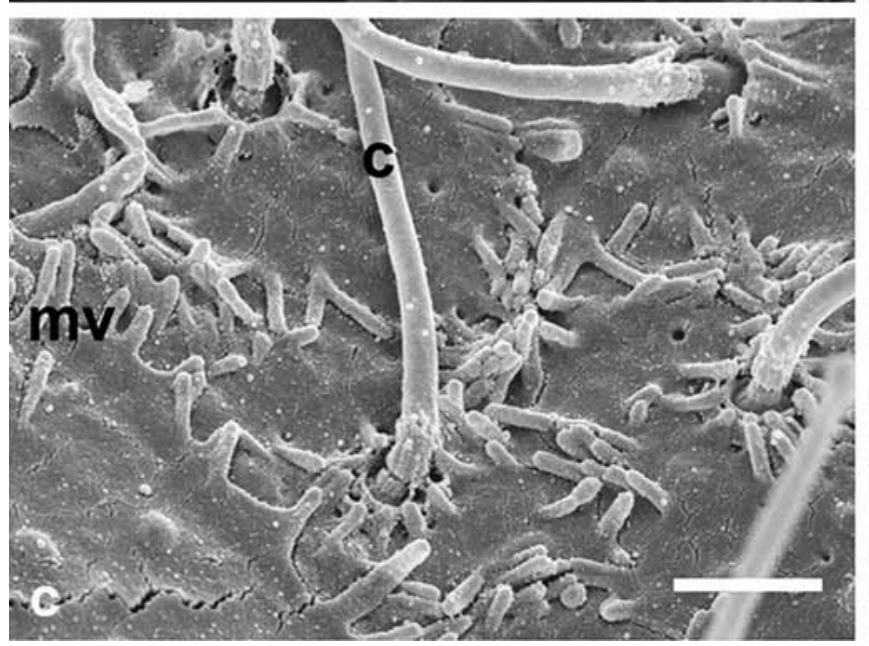

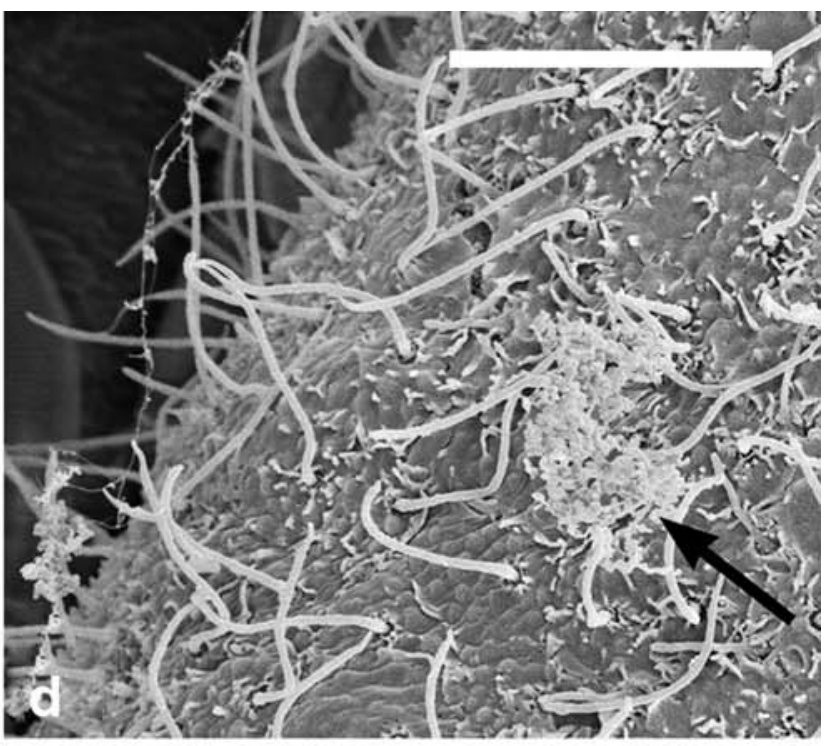

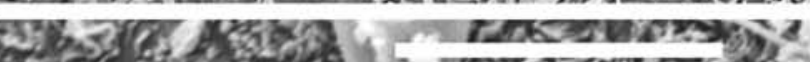
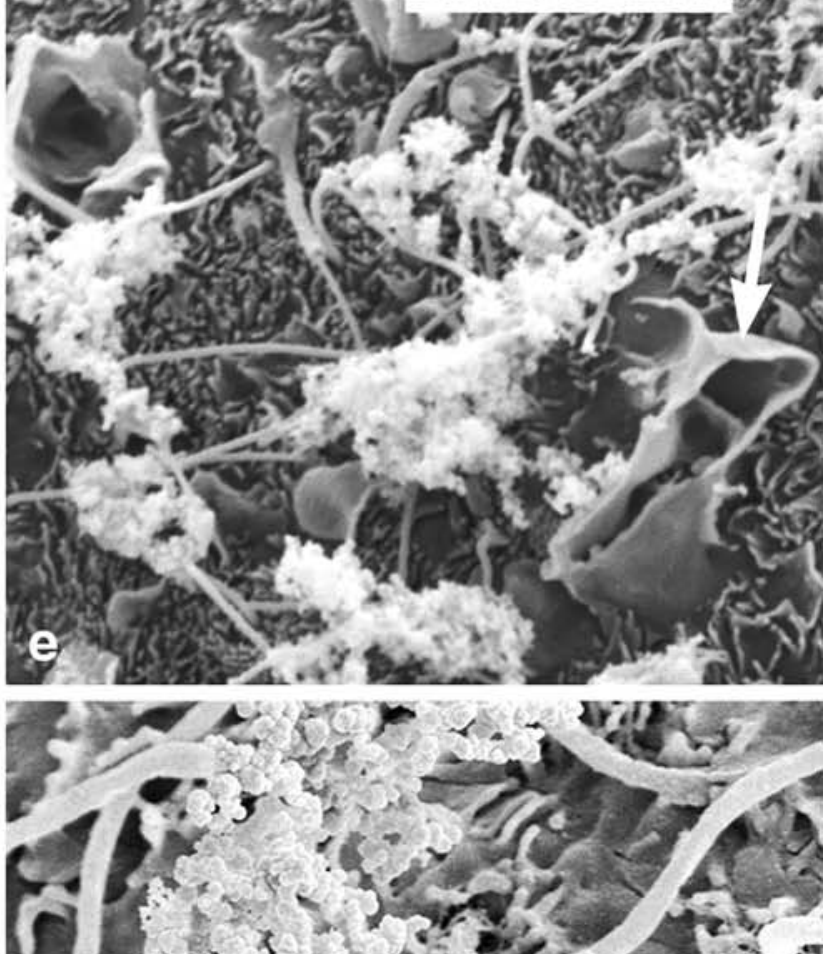

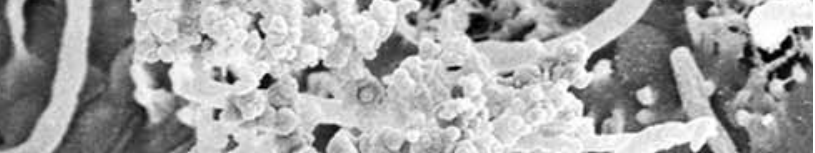

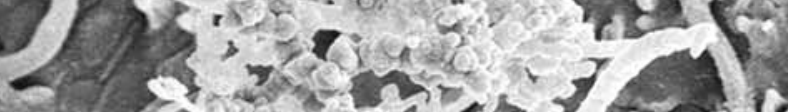

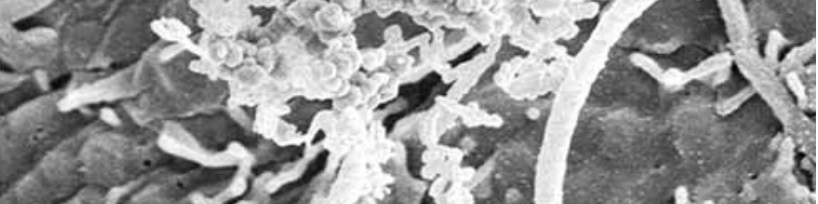

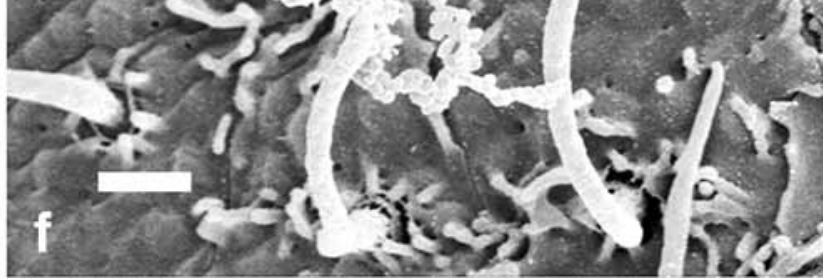


4 Fig. 2 a Low-resolution scanning electron micrograph of the surface of an expanded colony of Porites compressa showing portions of several individual polyps. The surfaces outside the rings of tentacles, and between the individual polyps, represent the coenenchymeof this coral. In all subsequent figures (except Figure 16) the surfaces being imaged are exclusively coenenchymal tissues. Scale bar $=0.5 \mathrm{~mm}$. b Cryofractured section through the two-cell-layer body wall of an expanded colony of $P$. compressa. The surface epidermis $(E)$, bathed in seawater, is separated from the gastrodermis $(G)$ by the thin mesogloea. The lumen below the gastrodermis is the gastrovascular cavity/ coelenteron ( $\mathrm{co}$ ) of the polyp The exposed surface of the epidermis is ciliated. Scale bar $=4 \mu \mathrm{m}$. $\mathrm{c}$ Detail of the ciliated surface of an expanded colony of $P$. compressa. The lateral margins of the individual

In some expanded specimens the ciliated external surface of the coral was partially obscured by circular cowls of material, which we are interpreting as mucus recently secreted by mucocytes (Fig. 3a-e). This material obscured the surface microvilli (Fig. 3b-e); sometimes it was penetrated by cilia (Fig. 3b) and sometimes the cilia were themselves also partially enveloped in this material (Fig. 3d-e). The material was sometimes revealed as an intact sheet (Fig. 3b-c) closely adhering to the external face of the cell membrane of the underlying epidermal cells; at other times the sheet, particularly at the edges of a cowl, seemed to have deteriorated from a solid sheet to one with a network of holes (Fig. 3d-e). The lateral spread (diameter) of these cowls varied from 10-25 $\mu \mathrm{m}$. Another feature of the surface of ciliated epidermal cells were slight protuberances of the cell membrane with circular profiles, $0.3 \mu \mathrm{m}$ in diameter (Fig. 3f).

\section{Surfaces of contracted $P$. compressa}

In those specimens that were only recently permanently contracted at the time of fixation, the surface of the coral tissue showed some markedly different features. Multilamellar sheets adhered closely to the surface of the coral tissue. These sheets were completely transparent to the naked eye in the in vivo state. After fixation, dehydration and critical point drying these sheets were still transparent, but could be visualized under a dissecting microscope using reflected light. Through these stages of specimen preparation, the sheets were mostly intact and continuous across the surface of the colony. In the process of sputter coating with gold and palladium (to form an electrically conducting surface layer on the specimen) these delicate structures usually shattered, but the multi-lamellar composition of the sheet was still apparent (Fig. 4a). Specimens in which this sheet was less than $24 \mathrm{~h}$ old were mostly free of any adherent material on the outside surface. The highest resolution images of a sheet at this stage indicated a granularity and porosity to this structure (Fig. $4 \mathrm{~b}$ ). These granules, $55-65 \mathrm{~nm}$ in diameter, appeared to be organized into chains. The chains ran in more than one plane within the sheet, and adjacent chains were separated by voids. epidermal cells are marked by interdigitating microvilli $(m v)$. The same type of microvilli surround the base of each cilium. c cilium; scale bar $=1 \mu \mathrm{m}$. d Ciliated coenenchymal tissue surface from an expanded colony of $P$. compressa. The tissue surface is mostly free of any adherent material except for a floculent mass (black arrow). Scale bar $=10 \mu \mathrm{m}$. e Flocs on the surface of an expanded colony of $P$. compressa were sometimes joined into elongate ropes. In specimens where greater concentrations of flocs were present, the epidermal tissue surface often showed increased evidence of active mucous secretion (white arrow). Scale bar $=10 \mu \mathrm{m}$. f Detail of the particulate composition of a floc on the surface of an expanded colony of $P$. compressa. Scale bar $=1 \mu \mathrm{m}$

In vivo visual observation of coral specimens in which the polyps had been permanently withdrawn for more than 2 days showed a fuzzy adherent layer on the colony surface, which over the next 1-3 days became inherently unstable and eventually sloughed off the coral completely. This fuzzy layer was revealed as a complex fouling community in the SEM (Fig. 4c, d), with detrital flocs, presumably laden with microbes, and diatoms as the most obvious components. This community formed on the outer surface of a mucous sheet that was otherwise still closely apposed to the coral epidermis. The cryofractured specimen in Fig. $4 \mathrm{c}$ revealed intimate contact of sheet and epidermis; in other specimens the sheet had become separated from the ectoderm as a physical artifact of specimen preparation, although such specimens again revealed the multi-lamellar character of the sheet (Fig. 4d). In specimens where the sheet had split away from the ectoderm the surface morphology of the epidermis was revealed (Fig. 4e). Protruding cilia and microvilli were completely absent from these cells, although the intercellular boundaries were still visible. There was no evidence of microbial organisms persisting under the sheet, although there was some indication of adherent granules in the same size range as those found on the outside surface of a sheet (as in Fig. 4b). The protuberances of Fig. 3f were replaced with what looked like shallow craters, $0.4 \mu \mathrm{m}$ diameter, on the epidermal cells (Fig. 4e). In those specimens with the most visible in vivo fuzzy appearance the surface fouling community revealed by SEM was the thickest and most diverse (Fig. 4f). This stage in the development of a microbial sheath was often very unstable, such that minor mechanical disturbance or agitation of the water column in contact with the coral, resulted in the whole structure being sloughed off the surface of the coral colony.

\section{Discussion}

With the techniques used in this study, fully expanded colonies of $P$. compressa revealed no discernable permanently adhered microbial community on the coral's coenosteal surface (Fig. 2b, c). The flocs and ropes of detrital material 

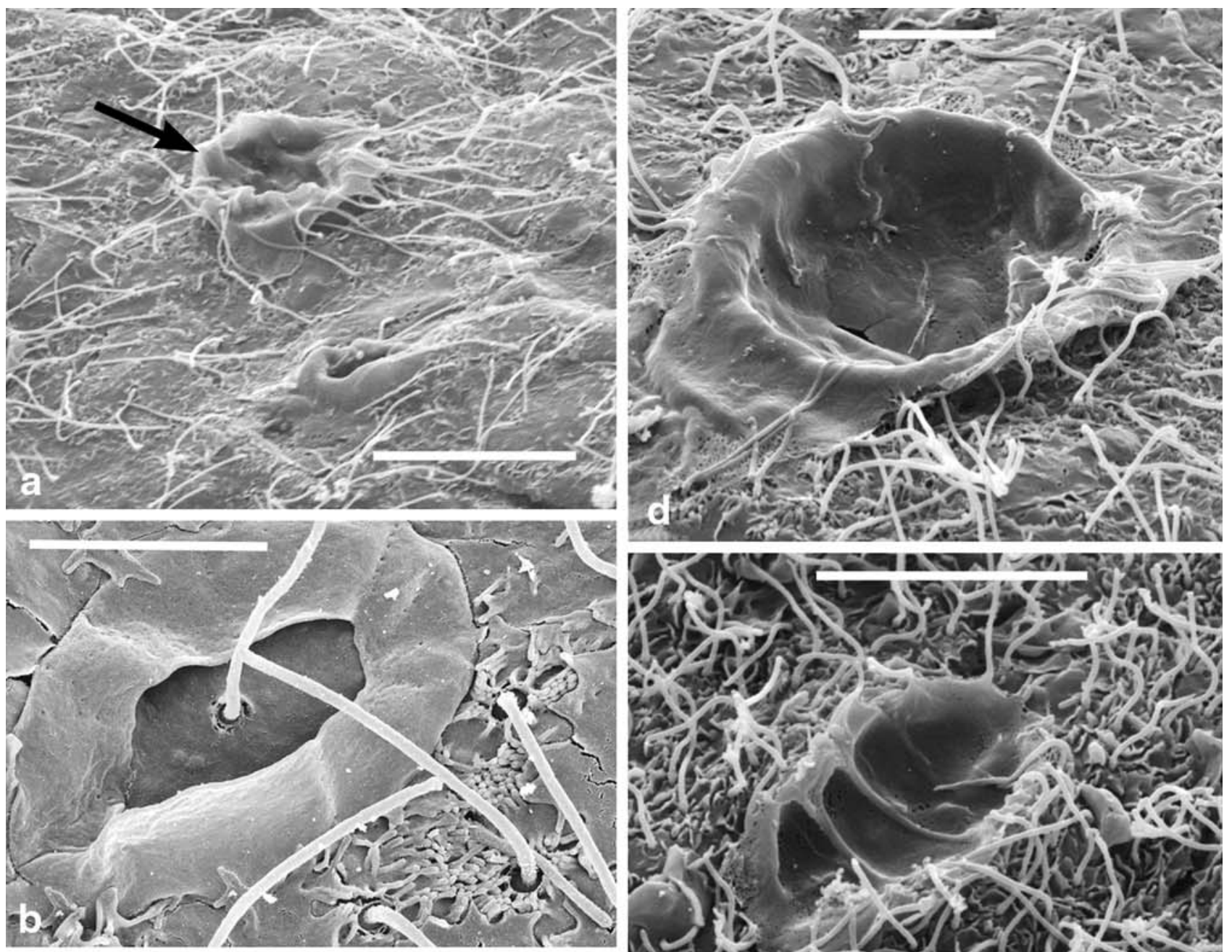

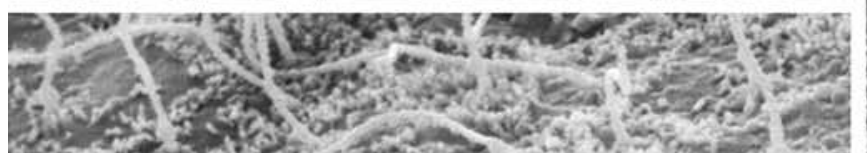
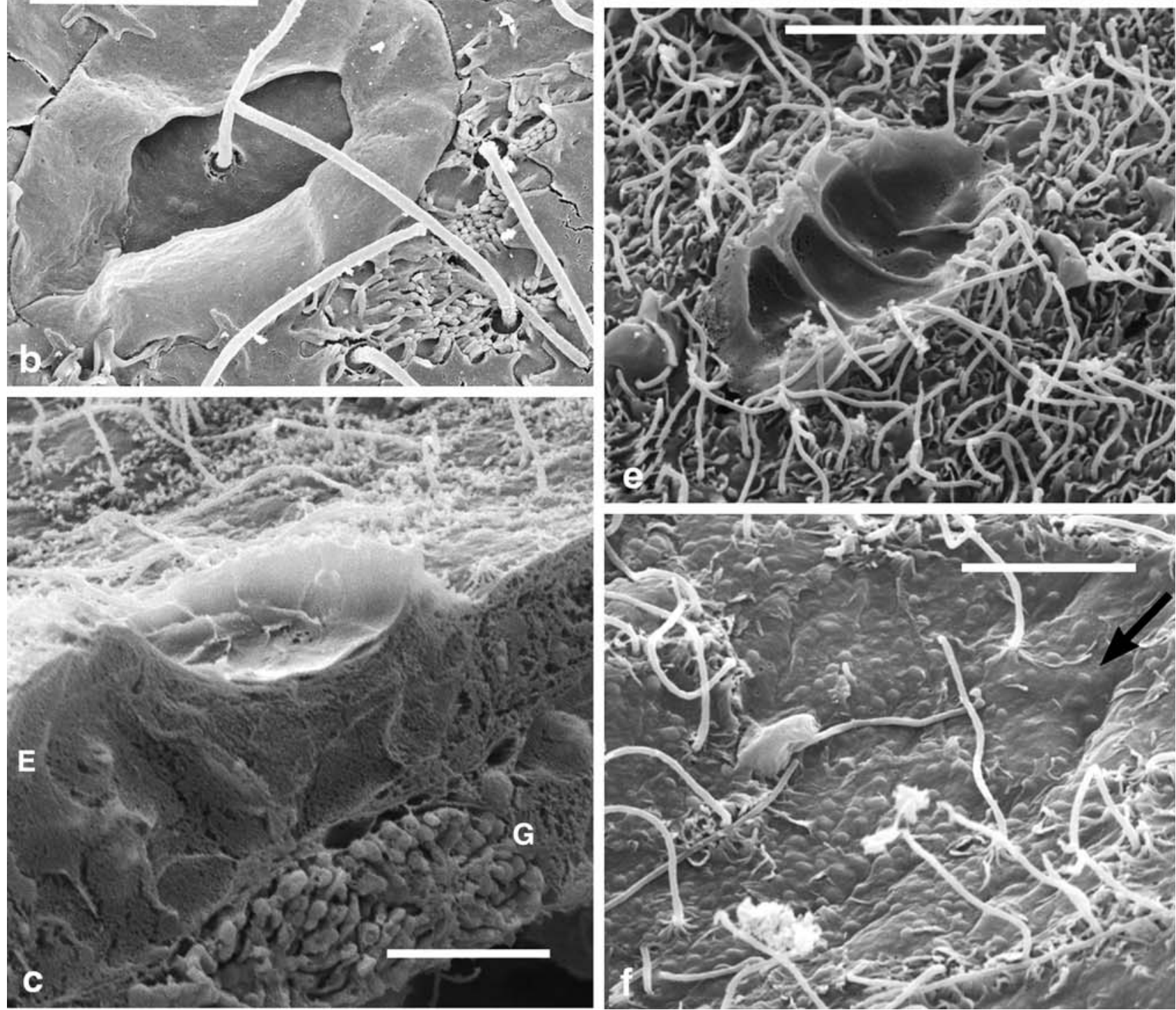
Fig. 3 Features on the surface of expanded colonies of Porites compressa, interpreted as stages in the secretion and subsequent dissolution of mucus produced by epidermal mucocytes. a Mucous remnants partially obscuring the ciliated epidermal surface. Scale bar $=15 \mu \mathrm{m}$. b High resolution image of a mucous remnant forming a partially collapsed cowl penetrated by a single cilium. Scale bar = $5 \mu \mathrm{m}$. c Cryofractured specimen providing a cross section through a cowl. The base of the cowl is a continuous sheet closely apposed to the epidermis underneath. $E$ epidermis, $G$ gastrodermis; scale bar $=5 \mu \mathrm{m}$.

(Fig. 2d-f) are interpreted as transient suspended sediment, or the components of marine snow, that had come in contact with the coral surface and had then been swept along the surface of the coral by the combined effects of enmeshing coral-mucus and ciliary beating. The shallow waters of Kaneohe Bay with which the running-seawater aquaria at HIMB were supplied, are characteristically high in sediment load, and each day the bottoms of the aquaria revealed piled sediment around the base of each whole coral colony, which had presumably been swept off the coral tissue.

The white reflective granules which dominate the calice rims of some terminal branch tips appear similar in size and appearance to those shown by Kramarsky-Winter et al. (2006) and thought to be stramenopile protists. However the ones shown here do not accumulate on the outer ectodermal surface, they do not fluoresce, and they do not stain with SYBR Green DNA stain (data not shown). Microbial adherence to the outer surfaces of reef corals has been demonstrated in the case of elevated-temperature-induced Vibrio shiloi infections of Oculina diffusa, but even here the adhesion is mediated through coral mucus (see review by Rosenberg 2004).

Mucocytes are a dominant cell type within the epidermis of reef-corals. The cowls of mucus, presumably caught just after secretion from the coral, have previously been demonstrated in Mycetophyllia reeesi (Goldberg 2002), although in that case they were interpreted as crater-like voids resulting from the exhaustive apocrine discharge of mucocytes. The transient membrane-like floor and wall of a cowl (Fig. 3b, c) might represent chemically fixed mucus at a stage just before effective dissolution in seawater or just before mechanical dispersal by cilia. The transition to a sheathed contracted colony (Fig. 4a) will require coordinated secretion of large amounts of mucus (maybe even a different type of mucus), as well as the removal/resorption of cilia. Under these circumstances the secreted material appears to polymerize into a multi-lamellar sheet rather than simply dissipating into the water column. Within $24 \mathrm{~h}$ of formation this sheet remains free of adherent microbes, but thereafter a typical fouling community begins to develop on the sheet and increases in thickness and structural diversity (and presumably biological diversity too) over the next $24-48 \mathrm{~h}$. This fouling community was not obviously different from fouling communities that developed on the bare surfaces of the plastic splint to which the d Crater-like cowl with the edges collapsed over adjacent epidermal cells. Scale bar $=5 \mu \mathrm{m}$. e Small crater-like cowl with evidence of cilia enveloped beneath the collapsed mucus. Scale bar $=10 \mu \mathrm{m}$. f Exposed coenenchymal surfaces from an expanded colony of $P$. compress $a$ reveals a cell-membrane topography comprising multiple $0.3 \mu \mathrm{m}$ protruberances (black arrow). These protruberances are interpreted as secretory granules lying just below the membrane in the cell cytoplasm. Scale bar $=5 \mu \mathrm{m}$

coral was attached. The microbial complement on top of the sheet probably accrues from mechanical sedimentation from the water column, by chemotactic attraction (recruitment) of motile microorganisms, as well as by growth in situ. We would speculate that the sheathing community benefits from dissolved organic metabolites leaked to it from the underlying coral.

The fact that microbial sheaths occur frequently among otherwise healthy colonies of $P$. compressa indicates the likelihood of benefit accruing to the coral from an adjacent sheath community, e.g. nitrogen fixation by members of this community, with some of that nitrogen becoming accessible to metabolism in the coral. Speculations about mutual interactions between corals and microbial communities associated with coral-surface mucopolysaccharide layers have been made before (Ritchie and Smith 2004).

Although the end-stage, or sloughing, of a typical fouled sheet was not documented among the SEM specimens shown here, it is presumed that this may well correlate with the renewed synthesis of epidermal cilia (providing destabilization from below) as well as by mechanical disturbance (from above by external water motion). Until the fouled sheet becomes destabilized the underlying multi-lamellar sheet remains complete and intact; it is literally a physical barrier over the epidermis. This physical barrier does have porosity to it (Fig. 4b) allowing dissolved materials to diffuse in either direction, albeit at reduced rates of movement. On the reef, the presence of an early mucous sheet is indicated on these corals by accumulating gas bubbles trapped at the surface of the coral by an otherwise invisible barrier.

The question arises, how might these cyclical changes at the surface of poritid species have affected previous efforts to harvest and characterize coral-associated microbial samples? Soft-tissue air-brushing of colonies of Porites astreoides and Porites furcata by Rohwer et al. (2001) might well have picked up the flocs and ropes from expanded colonies, or even early stages of mucous-sheet formation; early sheet formation is not visible to the naked eye of the diver/collector, except by the occurrence of prolonged polyp contraction. Whole-animal maceration of coral specimens (e.g., Klaus et al. 2005) would also sample the mucus layers of the coral surface, as well as commensals and endosymbionts from the coral gut and also add endolithic microbial components from the underlying skeleton. The absence of an adherent 

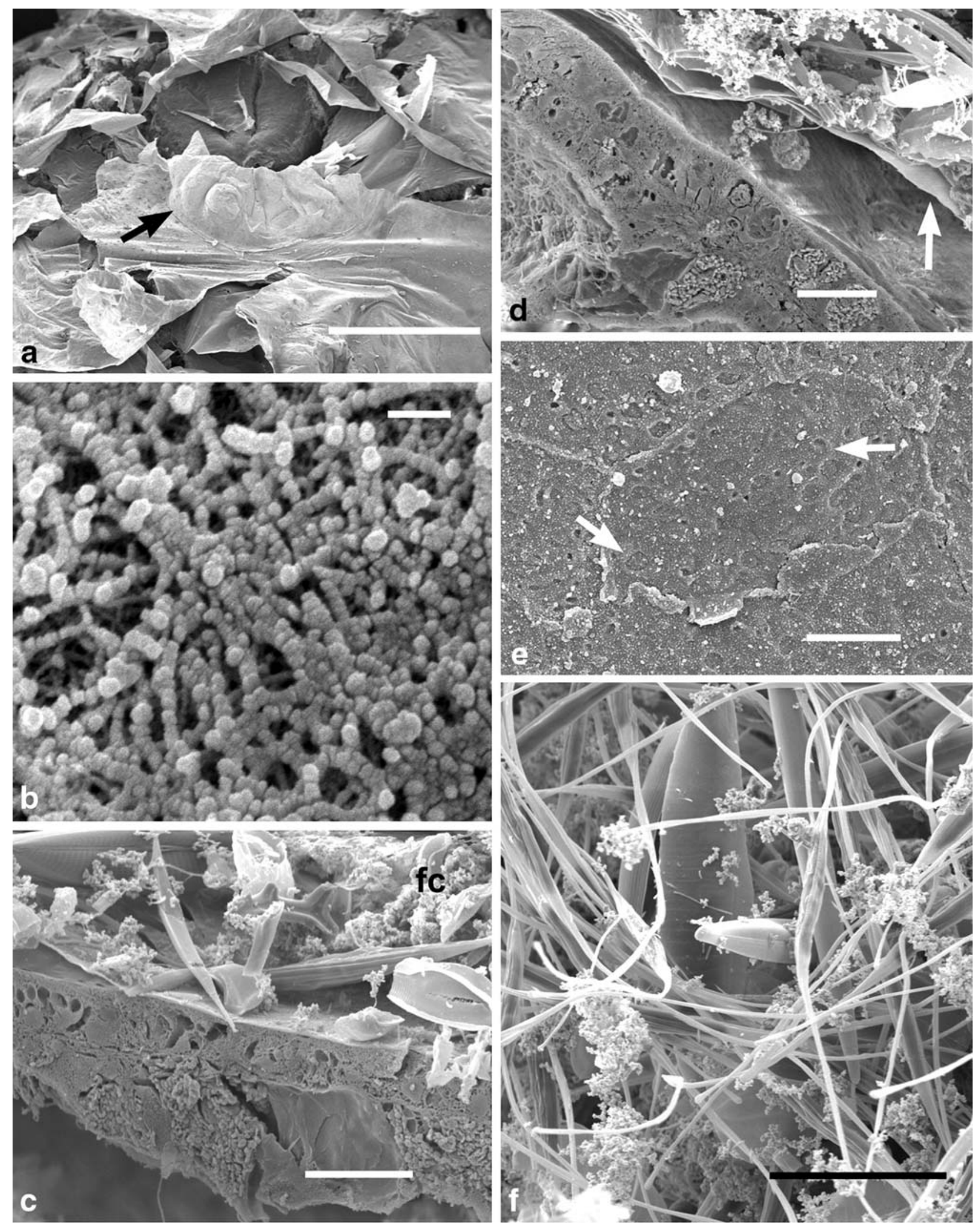
4Fig. 4. a Low resolution image of an early complete mucous sheet from a contracted specimen of Porites compressa. The sheet is shattered and torn but still reveals a partial mold of an underlying contracted polyp (black arrow). The specimen also shows that the mucous sheet as a whole is made up of multiple individual layers. Scale bar $=1 \mathrm{~mm}$. b High resolution image of an intact portion of a mucous sheet. Under the particular conditions of specimen preparation the sheet reveals a substructure of 55-65 nm diameter granules organized into chains. Scale bar $=0.2 \mu \mathrm{m}$. c Cryofractured specimen of a contracted specimen of $P$. compress $a$ with a highly fouled mucous sheet. The sheet is mostly in intimate contact with the epidermis, and the surface in contact with the bathing seawater comprises a complex fouling community $(f c)$. Diatoms and detrital flocs are particularly prominent in this community. Scale bar $=10 \mu \mathrm{m}$. d Cryofractured specimen of a contracted specimen of $P$. compressa in which the

microbial biofilm on the surface of expanded colonies does not preclude the possibility of a dynamic community of microorganisms hovering in the boundary layers of water immediately above the epidermis.

Acknowledgments This work was funded by the Marine Microbial Initiative from the Gordon and Betty Moore Foundation to FR. Field collections in Hawaii were approved by the Hawaii Department of Land and Natural Resources under permit \#PRO-2005-15. Paul Jokiel and his colleagues at HIMB provided kind hospitality in Hawaii. This is HIMB contribution \#1261.

\section{References}

Azam F, Worden AZ (2004) Microbes, molecules and marine ecosystems. Science 303:1622-1624

Brown BE, Bythell JC (2005) Perspectives on mucus secretion in reef corals. Mar Ecol Prog Ser 296:291-309

Coffroth MA (1985) Mucous sheet formation on poritid corals: effects of altered salinity and sedimentation. Proc 5th Int Coral Reef Symp 4:165-171

Coffroth MA (1990) Mucous sheet formation on poritid corals: an evaluation of coral mucus as a nutrient source on reefs. Mar Biol 105:39-49

Coffroth MA (1991) Cyclical mucous sheet formation on poritid corals in the San Blas Islands, Panama. Mar Biol 109:35-40

Coles SL, Strathmann R (1973) Observations on coral mucus "flocs" and their potential trophic significance. Limnol Oceanogr 18:673-678

Delbeek JC, Sprung J (1994) The reef aquarium; a comprehensive guide to the identification and care of tropical marine invertebrates. Ricordea, Coconut Grove

Fenner D (2005) Corals of Hawaii. Mutual, Honolulu

Goldberg WM (2002) Feeding behavior, epidermal structure and mucus cytochemistry of the scleractinian Mycetophyllia reesi, a coral without tentacles. Tissue Cell 34:232-245

Humphreys WJ, Spurlock BO, Johnson JS (1974) Critical point drying of ethanol-infiltrated, cryofractured biological specimens for scanning electron microscopy. In: Scanning electron microscopy/ 1974, ITT Research Institute, Chicago, pp 275-282

Johnston IS, Hildemann WH (1982) Cellular organization in the marine demosponge Callyspongia diffusa. Mar Biol 67:1-7 fouled sheet (white arrow) is split away from the epidermal surface as an artifact of specimen preparation; the sheet reveals its multilamellar composition. Specimens like this allowed access to the free/aboral surface of the epidermal cell layer (Fig. 4e). Scale bar $=10 \mu \mathrm{m}$. e A highly fouled $P$. compressa in which the sheathing community has split away during specimen preparation revealing a face-on view of the epidermal surface. No cilia or surface microvilli are present (cf Figs. 2c, 3f), although the lateral boundary of a single cell is apparent. The cell membrane surface is pocked with shallow $0.4 \mu \mathrm{m}$ craters (white arrows). Scale bar $=2 \mu \mathrm{m}$. f Surface view of a highly fouled mucus sheet from a contracted $P$. compressa. The resolvable components of this fouling community comprise diatoms, detrital flocs, filaments reminiscent of cyanobacteria and individual bacteria adherent to diatom surfaces. Scale bar $=10 \mu \mathrm{m}$

Jokiel PL (2004) Temperature stress and coral bleaching. In: Rosenberg E, Loya Y (eds) Coral health and disease. Springer, Heidelberg, pp 401-425

Kellogg CA (2004) Tropical Archaea: diversity associated with the surface microlayer of corals. Mar Ecol Prog Ser 273:81-88

Klaus JS, Frias-Lopez J, Bonheyo GT, Heikoop JM, Fouke BW (2005) Bacterial communities inhabiting the healthy tissues of two Caribbean reef corals: interspecific and spatial variation. Coral Reefs 24:129-137

Kramarsky-Winter E, Harel M, Siboni N, Ben Dov E, Brickner I, Loya Y, Kushmaro A (2006) Identification of a protist-coral association and its possible ecological role. Mar Ecol Prog Ser 317:67-73

Patterson KL, Porter JW, Ritchie KB, Polson SW, Mueller E, Peters ES, Santavy DL, Smith GW (2002) The etiology of white pox, a lethal disease of the Caribbean elkhorn coral, Acropora palmata. Proc Natl Acad Sci USA 99:8725-8730

Richmond RH (1993) Coral reefs: present problems and future concerns resulting from anthropogenic disturbance. Am Zool 33:524-536

Ritchie KB, Smith GW (2004) Microbial communities of coral surface mucopolysaccharide layers. In: Rosenberg E, Loya Y (eds) Coral health and disease. Springer, Heidelberg, pp 259-264

Rohwer F, Kelly S. (2004) Culture-independent analyses of coral-associated microbes Coral health and disease. In: Rosenberg E, Loya Y (eds) Coral health and disease. Springer, Heidelberg, pp 265278

Rohwer F, Breitbart M, Jara J, Azam A, Knowlton N (2001) Diversity of bacteria associated with the Caribbean coral Montastraea franksi. Coral Reefs 20:85-91

Rohwer F, Seguritan V, Azam F, Knowlton N (2002) Diversity and distribution of coral-associated bacteria. Mar Ecol Prog Ser 243:1-10

Rosenberg E (2004) The bacterial disease hypothesis of coral bleaching. In: Rosenberg E, Loya Y (eds) Coral health and disease. Springer, Heidelberg, pp 445-461

Rublee PA, Lasker HR, Gottfried, Roman MR (1980) Production and bacterial colonization of mucus from the soft coral Briarium asbestinum. Bull Mar Sci 30:888-893

Wegley L, Yu Y, Breitbart M, Casas V, Kline DI, Rohwer F (2004) Coral-associated Archaea. Mar Ecol Prog Ser 273:89-96

Wild C, Huettel M, Klueter A, Kremb SG, Rasheed MYM, Jorgensen BB (2004) Coral mucus functions as an energy carrier and particle trap in the reef ecosystem. Nature 428:66-70

Wilkinson C (2004) Status of coral Reefs of the world: 2004 Volumes 1 and 2. Australian Institute of Marine Science, Townsville 